\title{
Global time trends in the incidence of esophageal squamous cell carcinoma
}

\author{
Qiao-Li Wang' \\ Shao-Hua Xie' \\ Karl Wahlin' \\ Jesper Lagergren ${ }^{1,2}$
}

'Upper Gastrointestinal Surgery, Department of Molecular Medicine and Surgery, Karolinska Institutet, Karolinska University Hospital, Stockholm, Sweden; ${ }^{2}$ School of Cancer Sciences, King's College London, London, UK
Correspondence: Qiao-Li Wang Upper Gastrointestinal Surgery, Department of Molecular Medicine and Surgery, Karolinska Institutet, NS 67, 2nd Floor, Stockholm 17176, Sweden

Tel +468517 70940

Fax+46851776280

Email qiaoli.wang@ki.se
This article was published in the following Dove Press journal:

Clinical Epidemiology

Background and aims: Esophageal squamous cell carcinoma (ESCC) is the dominant histological type of esophageal cancer worldwide (90\%). We aimed to provide an update of the global temporal trends in the incidence of ESCC.

Methods: Incidence data for ESCC were collected from 30 well-established cancer registries from 20 countries in Europe, Northern America, Australia, or Asia for 1970-2015. Time trends in annual age-standardized incidence rates of ESCC were assessed using joinpoint analysis and log-linear regression. Age-period-cohort analysis was used to estimate the influence of age, calendar-period, and birth-cohort on the observed time trends in incidence.

Results: The age-standardized incidence rates of ESCC varied more than eightfold in men and sevenfold in women across populations. In 2012, the highest rate of ESCC in men was observed in Nagasaki, Japan (9.7/100,000 person-years) and in women in Scotland (2.7/100,000 personyears). In men, the incidence decreased globally during the study period, as well as during the last few years. In women, the incidence increased in Japan (three regions), the Netherlands, New Zealand, Norway, and Switzerland, whereas it stabilized or decreased in other populations. Among ethnic groups in the United States, black men and women had more pronounced decreases in incidence than other groups. Generally, birth-cohort effects were stronger determinants of incidence trends than calendar-period effects.

Conclusion: In men, the global ESCC incidence has decreased over time. In women, the incidence trends vary across populations, and the rates have increased in some countries. Changes in the prevalence of tobacco smoking and alcohol consumption may have contributed to these time trends.

Keywords: esophageal cancer, esophageal neoplasm, occurrence, worldwide, epidemiology

\section{Introduction}

Esophageal cancer is the sixth leading cause of cancer-related death globally, accounting for 440,000 deaths in 2013. ${ }^{1}$ Esophageal squamous cell carcinoma (ESCC) represents $90 \%$ of all cases of esophageal cancer worldwide. ${ }^{2,3}$ The main risk factors for ESCC are tobacco smoking and overconsumption of alcohol, particularly in combination. ${ }^{3}$ In 2012, the estimated age-standardized incidence rate was $<5 / 100,000$ person-years in both sexes in most Western countries, whereas it was $>13 / 100,000$ person-years in men and $>4 / 100,000$ person-years in women in Eastern and Southeast Asian countries. $^{2}$ In an analysis of a few Asian countries up to the year 2007, the ESCC incidence was decreasing in Hong Kong, Israel, and Singapore, and stable in Japan. ${ }^{4}$ Studies of Western populations have found linear declines in the incidence of ESCC in Australia, 
Sweden, and the United States in 1984-2008, ${ }^{5}$ and decreasing or stable incidence trends in European men, but increasing trends in women from Austria, Denmark, Estonia, Slovakia, and Switzerland, in 1980-2002. ${ }^{6}$ However, recent global time trends have not been assessed. With the collection of the most updated incidence data from well-established cancer registries across the world, this study aimed to assess the recent global time trends in the incidence of ESCC.

\section{Methods}

\section{Design}

Data were retrieved from 30 population-based cancer registries in 20 countries during January 1, 1970 to December 31, 2015 (varying across registries). All included registries have been evaluated for high completeness and quality of the data recorded. ${ }^{7}$ Cancer registries with incomplete histological information for esophageal cancer were excluded. The requested variables were the number of newly diagnosed ESCCs, calendar year of diagnosis, age at diagnosis (in 5-year groups), sex, and size of the background population at risk. The registries represented the following populations (in alphabetical order): Australia (Australian Capital Territory, New South Wales, South Australia, Tasmania, and Western Australia), China (Hong Kong), Croatia (nationwide), Finland (nationwide), France (Calvados), Iceland (nationwide), Ireland (nationwide), Italy (Veneto), Japan (Hiroshima, Miyagi, and Nagasaki), Kuwait (nationwide), Netherlands (nationwide), New Zealand (nationwide), Norway (nationwide), Slovenia (nationwide), Spain (Asturias, Granada, and Tarragona), Sweden (nationwide), Switzerland (almost nationwide), Thailand (Chiang Mai), United Kingdom (England, Scotland, and Wales), and United States (the Surveillance, Epidemiology and End Results [SEER] program). To assess the incidence time trends in the United States, including ethnicity-specific data, two combinations of the SEER registries were used: the SEER 9 registries (including the states Atlanta, Connecticut, Detroit, Hawaii, Iowa, New Mexico, San Francisco-Oakland, Seattle-Puget Sound, and Utah), with the longest registration period, and the SEER 18 registries (including all states in the SEER 9 registries plus the Alaska Native Tumor Registry, Greater California, Greater Georgia, Kentucky, Los Angeles, Louisiana, New Jersey, Rural Georgia, and San Jose-Monterey), with the widest geographic coverage. ${ }^{8,9}$ Data from the SEER registries were extracted from the SEER*Stat software version 8.3.3. Data from all other registries were collected by directly contacting the specific registries (contact persons are listed in Acknowledgments). Cancer registries that did not reply despite several attempts were mostly from developing countries. Data collected before 1970 were excluded to minimize differences in diagnosis coding practices between registries and, thus, make the results comparable across registries. In most registries, the diagnosis code $\mathrm{C} 15$ in the International Classification of Diseases, version 10 (ICD-10) defined the esophageal tumor site, and the histology codes 8050-8078 and 8083-8084 in the International Classification of Disease for Oncology, version 3 (ICD-O-3) represented squamous cell carcinoma. Detailed information about the registries included as well as coding of ESCC is presented in Table S1. Ethical approval and informed consent from participants were exempted because no personal records were accessed, and the study was based only on publicly available data of population sizes and aggregated data of cancer cases.

\section{Statistical analysis}

All analyses were stratified for sex. Data from regional registries within a country were merged to provide a wider geographic coverage and better statistical precision. Crosssectional analysis comparing several registries was conducted for 2012, which was the most recent year of data availability in the majority of registries. The country-specific agestandardized annual incidence rates were calculated using the direct method, based on the World Standard Population 2000 as the reference, and the corresponding 95\% CIs were estimated using the gamma distribution. Joinpoint analysis was conducted to identify change points in incidence trends, and to estimate the annual percentage change in each time segment before and after joinpoints. The annual percentage change was estimated on a log-linear scale under the assumption that the rate changed by a constant percentage every year on a log-scale within a specific time-period. The average annual percentage change - a weighted average of annual percentage changes from joinpoint models with weights equal to the length of each segment - was computed as a summary measure of the trend over the study period. A maximum of three predefined change points were allowed. Subgroup analyses by ethnicity (white, black, Asian/Pacific Islander, and American Indian/Alaska Native) were conducted on the basis of the SEER registries in the United States.

Age-period-cohort regression was used to evaluate the effects of age, calendar-period, and birth-cohort on the incidence rates of ESCC, using a web-tool developed by the National Cancer Institute in the United States. ${ }^{10}$ Period effects result from factors that affect all age groups equally at a particular calendar time (eg, introduction of new diagnostic methods in a certain calendar period), whereas cohort effects 
Table I Results from joinpoint analyses for selected registers

\begin{tabular}{|c|c|c|c|c|}
\hline Sex & Registry & Joinpoint (95\% Cl) & Period & Annual percentage change $(95 \% \mathrm{Cl})$ \\
\hline \multicolumn{5}{|l|}{ Men } \\
\hline & \multirow[t]{2}{*}{ Croatia } & \multirow[t]{2}{*}{2004 (200I, 2007) } & 1999-2004 & $1.9(-3.4,7.5)$ \\
\hline & & & $2004-2014$ & $-4.5(-6.3,-2.7)$ \\
\hline & \multirow[t]{2}{*}{ England } & \multirow[t]{2}{*}{1997 (1996, 1999) } & $1990-1997$ & $2.9(2.1,3.8)$ \\
\hline & & & $1997-20 \mid 4$ & $-0.7(-0.9,-0.5)$ \\
\hline & \multirow[t]{2}{*}{ France (Calvados) } & \multirow[t]{2}{*}{$1986(1980,1994)$} & $1978-1986$ & $-1.1(-5.5,3.4)$ \\
\hline & & & $1986-2013$ & $-5.1(-5.8,-4.4)$ \\
\hline & \multirow[t]{2}{*}{ Japan (three regions) } & \multirow[t]{2}{*}{$2005(1999,2008)$} & $1986-2005$ & $1.0(0.5,1.6)$ \\
\hline & & & $2005-2010$ & $-3.1(-7.2,1.1)$ \\
\hline & \multirow[t]{2}{*}{ Norway } & \multirow[t]{2}{*}{$1988(1980,1994)$} & $1970-1988$ & $0.8(-0.7,2.2)$ \\
\hline & & & $1988-20 \mid 4$ & $-2.2(-3.0,-1.3)$ \\
\hline & \multirow[t]{3}{*}{ Scotland } & I98I $(1977,2003)$ & $|975-198|$ & $4.8(1.2,8.5)$ \\
\hline & & \multirow[t]{2}{*}{$2000(1995,2007)$} & $|98|-2000$ & $1.0(0.4,1.7)$ \\
\hline & & & $2000-2014$ & $-2.6(-3.5,-1.6)$ \\
\hline & \multirow[t]{2}{*}{ Sweden } & \multirow[t]{2}{*}{$1987(1983,1990)$} & $1970-1987$ & $1.3(0.3,2.3)$ \\
\hline & & & $1987-2015$ & $-2.1(-2.6,-1.6)$ \\
\hline & \multirow[t]{2}{*}{ Switzerland } & \multirow[t]{2}{*}{$1988(1987,1994)$} & $1985-1988$ & $9.6(-3.6,24.5)$ \\
\hline & & & $1989-2012$ & $-1.3(-1.8,-0.7)$ \\
\hline & \multirow[t]{2}{*}{ The Unites States (SEER 9) } & \multirow[t]{2}{*}{$1986(1983,1989)$} & $1973-1986$ & $-0.4(-1.2,0.5)$ \\
\hline & & & $1986-2013$ & $-3.8(-4.1,-3.5)$ \\
\hline \multicolumn{5}{|c|}{ Women } \\
\hline & \multirow[t]{2}{*}{ England } & \multirow[t]{2}{*}{ I999 (I993, 200I) } & $1990-1999$ & $2.6(1.5,3.7)$ \\
\hline & & & $1999-2014$ & $-0.9(-1.4,-0.4)$ \\
\hline & \multirow[t]{2}{*}{ The Netherlands } & \multirow[t]{2}{*}{ I99I (199I, I996) } & |989-199| & $15.8(-9.2,47.8)$ \\
\hline & & & $|99|-20 \mid 4$ & $0.2(-0.3,0.8)$ \\
\hline & \multirow[t]{2}{*}{ Norway } & \multirow[t]{2}{*}{1987 (1972, 1999) } & $1970-1987$ & $2.8(I .1,4.5)$ \\
\hline & & & $|987-20| 4$ & $-0.6(-1.4,0.3)$ \\
\hline & \multirow[t]{2}{*}{ Scotland } & \multirow[t]{2}{*}{$1993(1990,1997)$} & $1975-1993$ & $2.4(1.5,3.2)$ \\
\hline & & & $1993-2014$ & $-1.3(-2.0,-0.6)$ \\
\hline & \multirow[t]{2}{*}{ The Unites States (SEER 9) } & \multirow[t]{2}{*}{1986 (1982, 1989) } & $1973-1986$ & $0.7(-0.6,2.0)$ \\
\hline & & & $1986-2013$ & $-2.9(-3.3,-2.5)$ \\
\hline
\end{tabular}

Abbreviation: SEER, The Surveillance, Epidemiology and End Results.

occur when the effect of an exposure is different across age groups (birth cohorts) in a certain period and are more likely to be associated with risk factors (eg, increased smoking prevalence in younger generations). The age-period-cohort modeling was applied with 5-year age groups (varying across registries), 5-year calendar-periods (varying across countries), and consequently spanned into partially overlapping 9-year birth-cohorts. The age-period-cohort regression was based on a log-linear model for the incidence rates with additive effects from age, calendar-period, and birth-cohort as shown in the formula:

$$
\rho_{p a}=\alpha_{a}+\beta_{p}+\gamma_{c}
$$

where $\rho_{p a}$ defines the expected incidence rate, and $\alpha_{a}, \beta_{p}$, and $\gamma_{c}$ represent the effects of age, calendar-period, and birth-cohort, respectively. The generic effects can be separated into linear and nonlinear components. The web tool used fits the age-period-cohort model, and estimates the sum of linear components of birth-cohort and calendar-period effects (net drift), which is equivalent to the overall annual percentage change in age-standardized rates. The age-group-specific annual percentage change (local drift) was generated from the log-linear regression analysis. The relative rate in any given calendar-period (or birth-cohort) versus a reference calendarperiod (or birth-cohort) was estimated with adjustment for age and nonlinear birth-cohort effects (or calendar-period effects).

The statistical software used was mainly SAS version 9.4 (SAS Institute, Cary, NC, USA), together with the Joinpoint Program (version 4.4.0.0, National Cancer Institute, United States) and the age-period-cohort web tool. All statistical tests were two-sided. 


\section{Results}

\section{Participants}

The study included 180,395 patients diagnosed with ESCC from 30 registries in 20 countries in 1970-2015. Of these, $109,630(60.8 \%)$ were men and 70,765 (39.2\%) were women. The median age at diagnosis was 67.5 years (interquartile range $62.5-77.5$ years).

\section{Incidence in 2012}

In men, the highest incidence rates in the year 2012 were observed in Nagasaki, Japan (9.7/100,000 person-years), Calvados, France (8.2/100,000 person-years), and Hong Kong, China (4.9/100,000 person-years), whereas the lowest rates were found in Finland and South Australia in Australia (both 1.2/100,000 person-years).

In women, the incidence rates in 2012 were generally lower than in men, with the highest rates in Scotland (2.7/100,000 person-years), Ireland (2.6/100,000 personyears), and Tasmania, Australia (2.0/100,000 person-years), and the lowest rates in Croatia, Spain (three regions) and Thailand (Chiang Mai; all 0.4/100,000 person-years).

The male-to-female ratio in 2012 was highest in Nagasaki, Japan (8.9:1) and Calvados, France (8.1:1), and lowest in Ireland (1.0:1) and South Australia, Australia (1.1:1).

\section{Incidence trends in 1970-20 I5}

In men, the incidence of ESCC decreased from 2000 onwards in most countries, except in Japan (three regions); however, the year when the decrease began varied across countries (Figure 1A). In 1990-2014, the incidence rate was gradually decreasing and relatively low ( $<4.0 / 100,000$ person-years) in North-Western European countries (Finland, Ireland, Norway, the Netherlands, Sweden, Switzerland, and the United Kingdom [three regions]), Oceanian countries (Australia [five regions] and New Zealand), and the United States (SEER 9; Figure 1A). A sharp decrease was observed in Calvados, France (from 28.6/100,000 person-years in 1979 to 6.4/100,000 person-years in 2013) and Hong Kong, China (from 10.1/100,000 person-years in 1994 to 5.0/100,000 person-years in 2013; Figure 1A). In contrast, the incidence increased by $1.0 \%(95 \%$ CI $0.5 \%-1.6 \%)$ annually in Japan (three regions) in 1986-2005, followed by a slight decrease in 2006-2010 (Figures 1A and 2A, and Table 1).

In women, the incidence trends increased, stabilized, or decreased, based on the country (Figure 1B). Increasing incidence trends were observed in Japan (three regions), the Netherlands, New Zealand, Norway, and Switzerland throughout the study period (Figures $1 \mathrm{~B}$ and $2 \mathrm{~B}$ ). In the
Netherlands and Spain (three regions), an annual increase of $>1.0 \%$ was identified during the study period. Joinpoints were found in the incidence trends both in the Netherlands and Norway in the 1990s; after the joinpoint, the incidence slightly increased in the Netherlands (annual percentage change $0.2 \%, 95 \% \mathrm{CI}-0.3 \%$ to $0.8 \%$ ), and was stable in Norway (annual percentage change $-0.6 \%, 95 \%$ CI $-1.4 \%$ to $0.3 \%$; Table 1 ). In contrast to most other countries, Hong Kong, China, and Finland showed strongly decreasing incidence rates (average annual percentage change $-4.0 \%$, $95 \% \mathrm{CI}-4.9 \%$ to $-3.1 \%$ and $-3.7 \%, 95 \% \mathrm{CI}-4.2 \%$ to $-3.1 \%$, respectively; Figure 2B). The incidence rates were low $(<1.5 / 100,000$ person-years $)$ in South European countries (Croatia, France [Calvados], Italy [Veneto], Slovenia, and Spain [three regions]) and were stable or slightly increasing over time, whereas the relatively high-incidence countries Ireland and the United Kingdom (three regions; $>2.0 / 100,000$ person-years) had slightly decreasing incidence rates over time (Figure 1B).

The male-to-female ratio ranged from 1.0:1 to $4.0: 1$ by country, and was stable over time in North-Western European countries, Oceanian countries, and the United States (Figure S1). In Asian (China [Hong Kong], Japan [three regions], and Thailand [Chiang Mai]) and South European countries (Croatia, France [three regions], Italy [Veneto], Slovenia, and Spain [three regions]), the male-to-female ratio ranged from 5.0:1 to 30.0:1, but decreased over time (Figure S1).

\section{Age-period-cohort analysis}

In men, interactions between calendar-period and birthcohort effects seem to have contributed to the decrease in incidence of ESCC (Table S2). The increase in incidence trends in Japanese men showed a calendar-period effect ( $P=0.021)$, but no birth-cohort effect $(P=0.059$; Table $\mathrm{S} 2)$. The analysis of age-specific percentage change indicated calendar-period effects in French men older than 50 years and Chinese men older than 40 years (Figure 3). Substantial birth-cohort effects were found in New Zealand $(P=0.045)$ and Spain (three regions; $P=0.004$; Table S2).

In women, the incidence trends of ESCC seem to have been influenced by both calendar-period and birth-cohort effects in most countries, including Australia (five regions), Croatia, Finland, Slovenia, Sweden, the United Kingdom (three regions), and the United States (SEER 9; Table S2). However, the increasing incidence in Norwegian women was due to a calendar-period effect $(P=0.046)$, especially in women aged 45-70 years (Table S2, Figure 3). A birth-cohort 
A
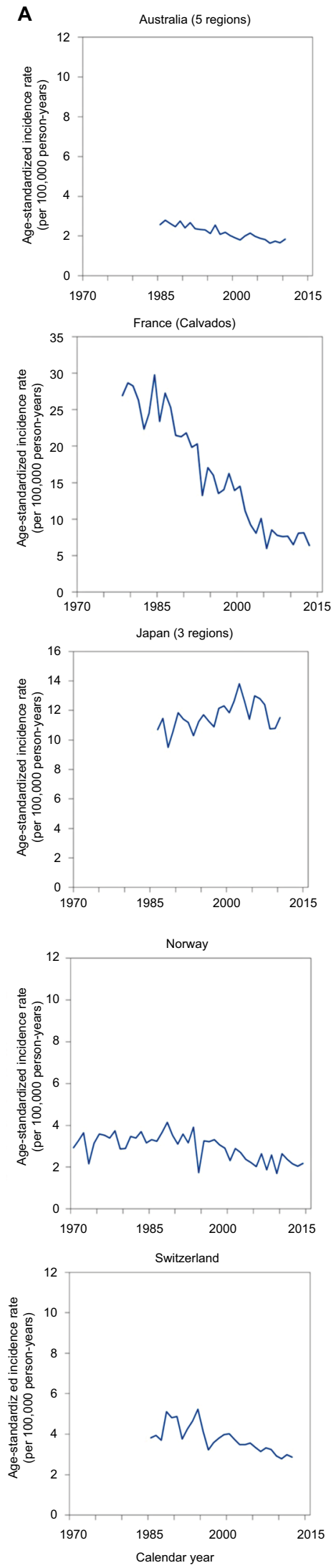
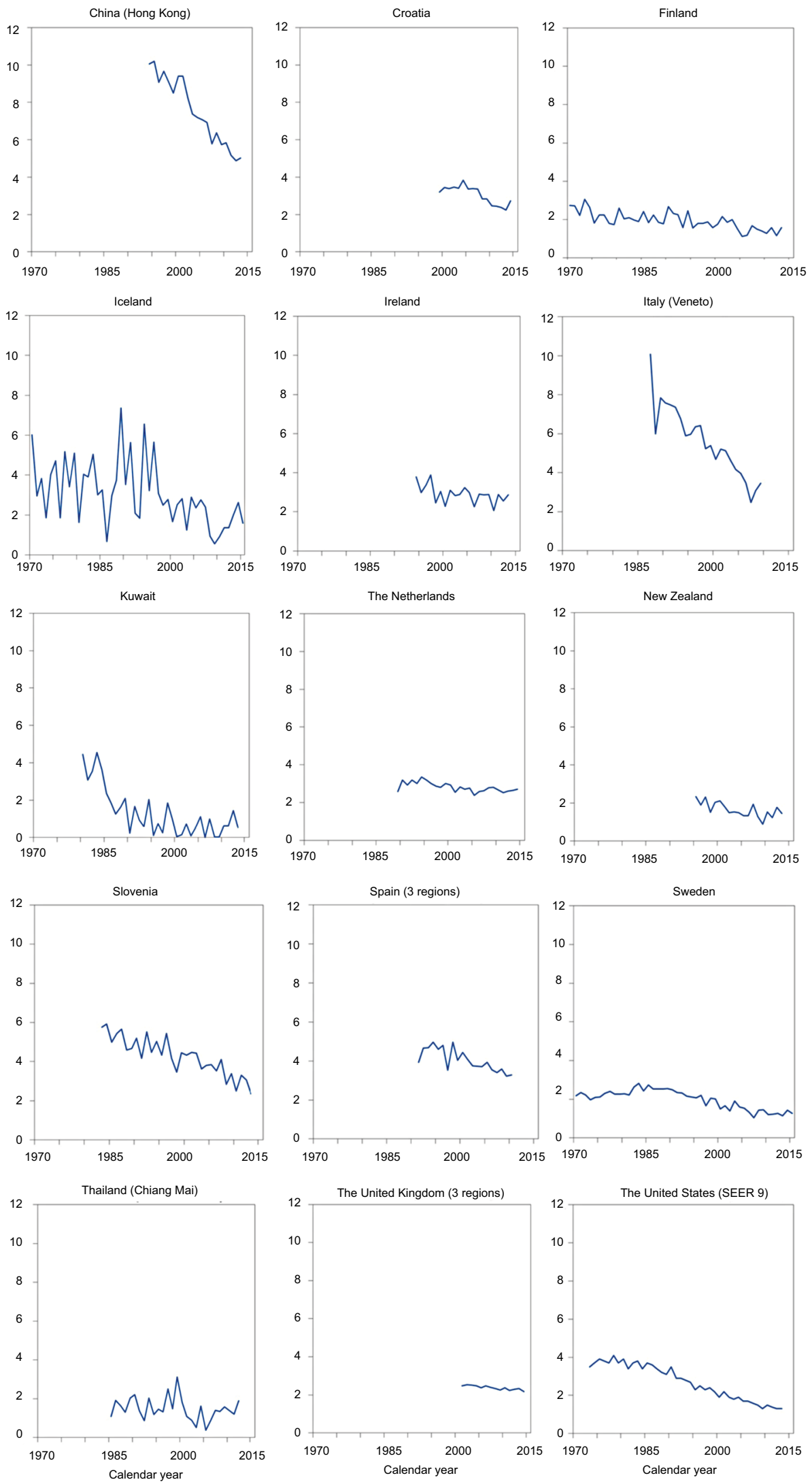

Figure I (Continued) 

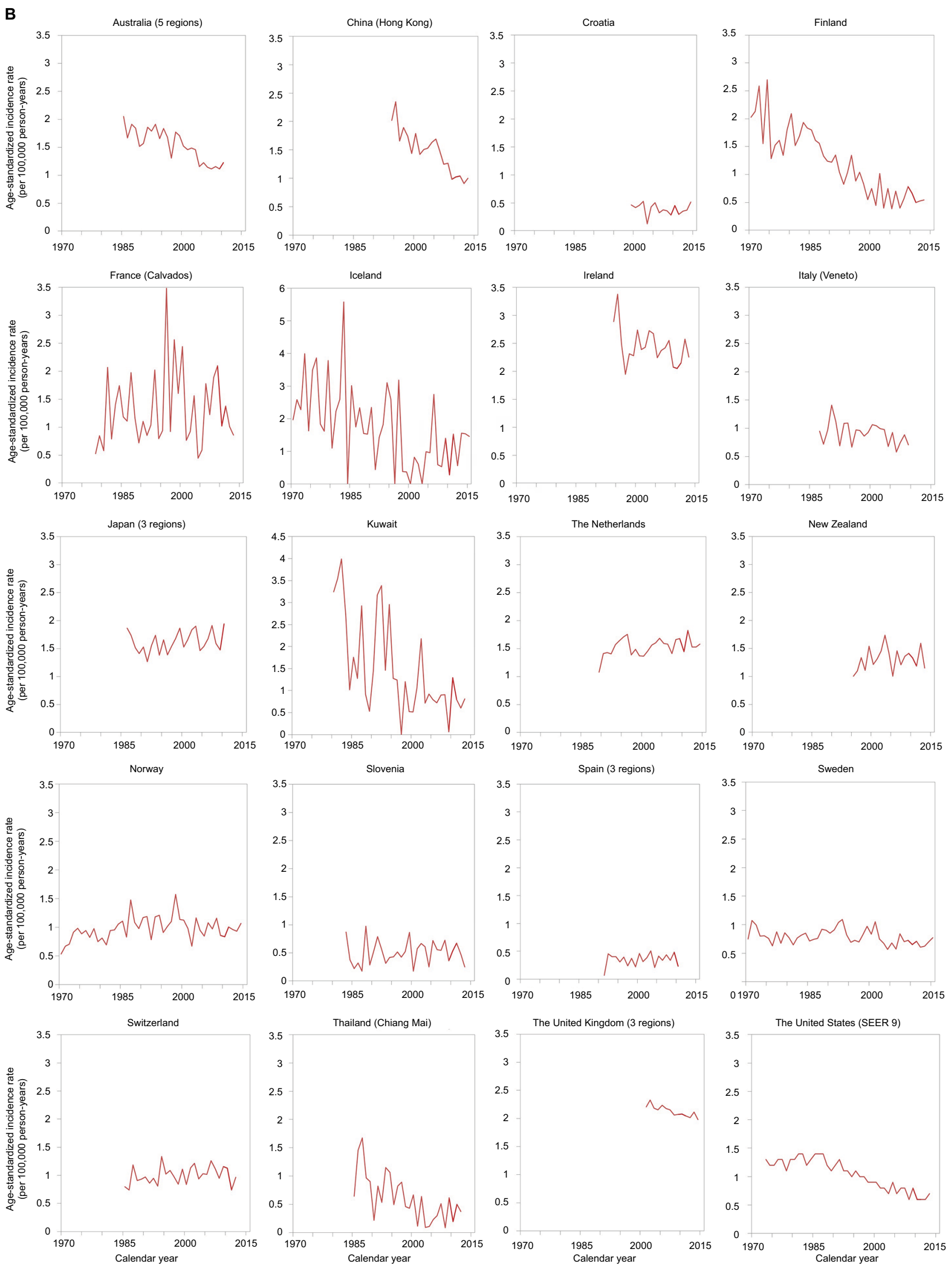

Figure I Global annual age-standardized incidence rates of esophageal squamous cell carcinoma in men (A) and women (B). Abbreviation: SEER, The Surveillance, Epidemiology and End Results. 
A

$\begin{array}{rr}\text { Country } & \begin{array}{l}\text { Average annual } \\ \text { percentage change }\end{array} \\ \text { Australia (5 regions) } & -1.9(-2.3,-1.6) \\ \text { China (Hong Kong) } & -4.0(-4.5,-3.5) \\ \text { Croatia } & -2.4(-4.3,-0.5) \\ \text { Finland } & -1.4(-1.8,-1.0) \\ \text { France (Calvados) } & -4.2(-5.3,-3.1) \\ \text { Iceland } & -2.2(-3.3,-1.0) \\ \text { Ireland } & -1.2(-2.4,-0.1) \\ \text { Italy (Veneto) } & -4.5(-5.3,-3.7) \\ \text { Japan (3 regions) } & 0.2(-0.8,1.1) \\ \text { The Netherlands } & -0.7(-1.1,-0.3) \\ \text { New Zealand } & -2.7(-4.3,-1.0) \\ \text { Norway } & -1.0(-1.7,-0.2) \\ \text { Slovenia } & -2.3(-2.7,-1.8) \\ \text { Spain (3 regions) } & -1.8(-2.6,-1.1) \\ \text { Sweden } & -1.4(-1.8,-0.9) \\ \text { Switzerland } & -0.9(-2.3,0.6) \\ \text { The United Kingdom (3 regions) } & -1.0(-3.3,0.9) \\ \text { The United States (SEER 9) } & -2.7(-3.0,-2.4)\end{array}$

B

$\begin{array}{rr}\text { Australia (5 regions) } & -2.1(-2.7,-1.6) \\ \text { China (Hong Kong) } & -4.0(-4.9,-3.1) \\ \text { Croatia } & -0.3(-4.3,3.9) \\ \text { Finland } & -3.7(-4.2,-3.1) \\ \text { Ireland } & -0.6(-1.0,2.2) \\ \text { France (Calvados) } & -1.9,0.1) \\ \text { Italy (Veneto) } & -1.4 .4 .2) \\ \text { Japan (3 regions) } & 0.4(-0.2,1.1) \\ \text { The Netherlands } & 1.4(-0.5,3.3) \\ \text { New Zealand } & 0.6(-0.7,2.0) \\ \text { Norway } & 0.7(-0.1,1.5) \\ \text { Slovenia } & 0.6(-1.3,2.6) \\ \text { Spain (3 regions) } & 1.9(-1.7,5.7) \\ \text { Sweden } & -0.4(-0.8,-0.1) \\ \text { Switzerland } & 0.5(-0.2,1.3) \\ \text { The United Kingdom (3 regions) } & -0.9(-8.7,-2.5) \\ \text { The United States (SEER 9) } & -1.8(-2.2,-1.3)\end{array}$
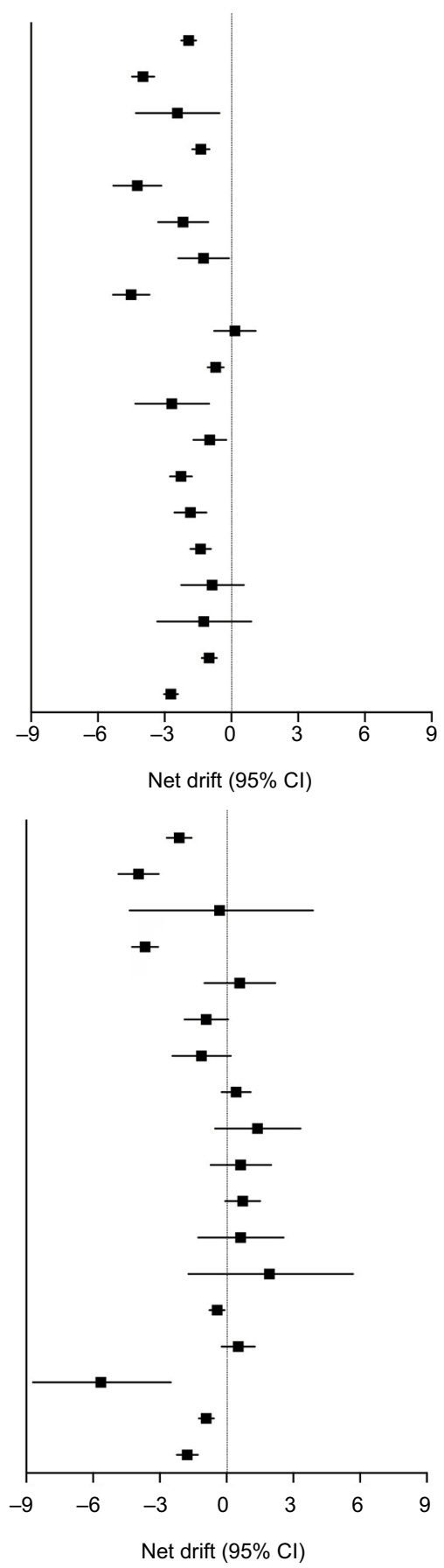

Figure 2 Average annual percentage change and $95 \% \mathrm{Cl}$ in the incidence of esophageal squamous cell carcinoma in men (A) and women (B). Abbreviation: SEER, The Surveillance, Epidemiology and End Results.

effect was indicated behind the increasing incidence in the Netherlands $(P<0.001)$, Switzerland $(P=0.014)$, and Japan (three regions; $P<0.001$; Table $\mathrm{S} 2$ ). An increased annual percentage change was found in women older than 60 years in the Netherlands and Switzerland, and in women aged 45-64 years in Japan (three regions; Figure 3). The birth-cohort-specific relative risk was $>1$ in Japan (three regions) and Norway in recent cohorts compared with the reference cohort, but $<1$ in the Netherlands and Switzerland (Figure S2). 

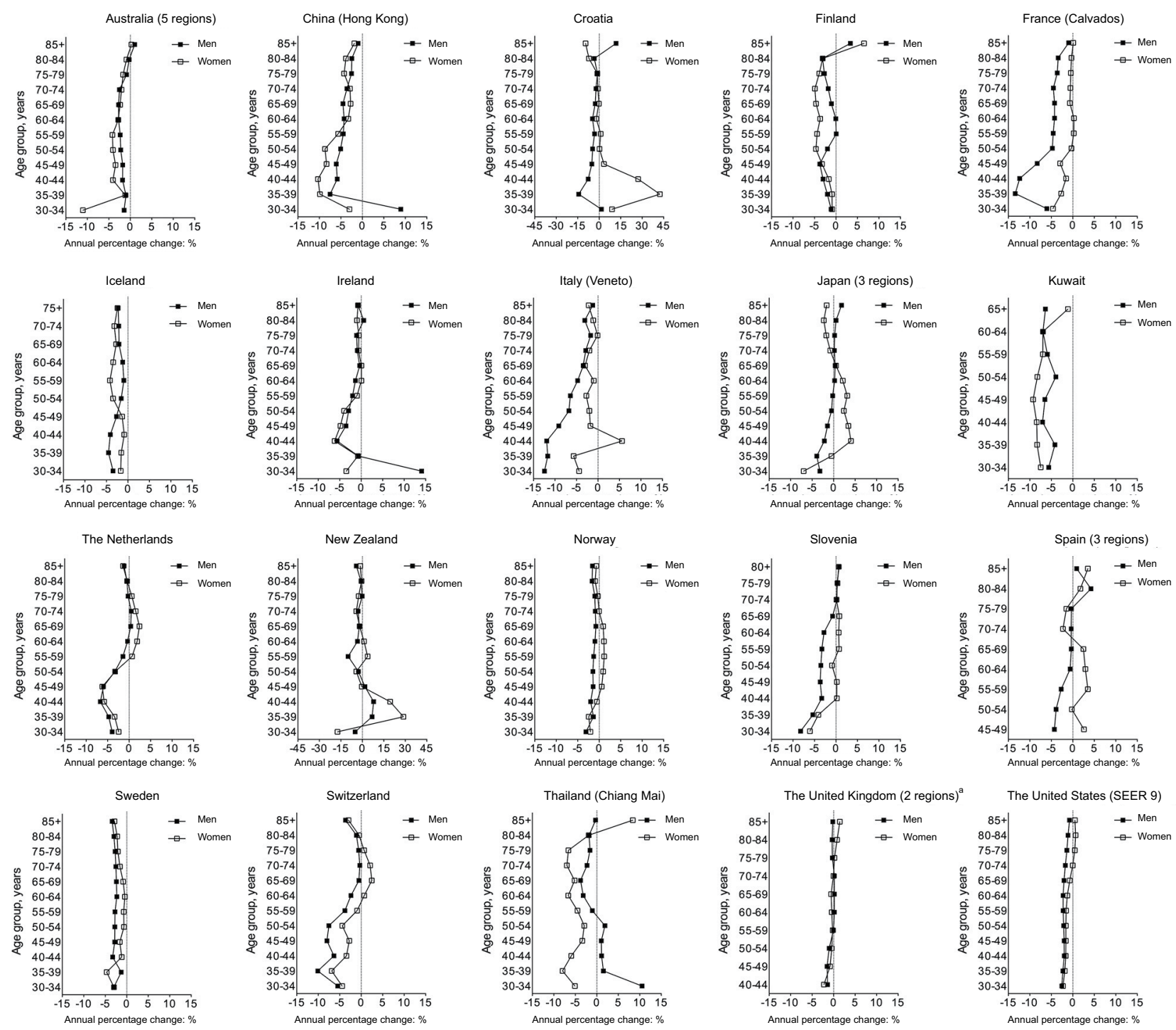

Figure 3 Age-specific annual percentage change (local drifts) in the incidence of esophageal squamous cell carcinoma stratified by sex. Note: ${ }^{2}$ Data from England and Scotland were merged and analyzed for the United Kingdom.

Abbreviation: SEER, The Surveillance, Epidemiology and End Results.

\section{Ethnicity}

The incidence of ESCC in the United States (SEER 9 and 18) was higher in black men and women than in white, Asian, Pacific Islander, American Indian, or Alaska Native groups (Figure 4A).

In men, the incidence in blacks increased from the year 1973 and peaked in 1986 (17.8/100,000 person-years), followed by a steady decrease to $3.6 / 100,000$ person-years in 2013. In white, Pacific, or Alaskan men, low incidence rates $(<3.0 / 100,000$ person-years) in the 1970 s were followed by a further slight decrease throughout the study period (Figure 4A).

In women, black women had an incidence rate of 1.4/100,000 person-years and white and Pacific or Alaskan women had an incidence of $0.5 / 100,000$ person-years in 2013 (Figure 4B). A relatively high incidence was found in black women in 1977-1992, peaking in the year 1981 at 5.6/100,000 person-years, and declining from 1993 onwards. In white and Pacific or Alaskan women, the incidence was low and continued to slightly decrease during the study period (Figure 4B).

\section{Discussion}

This global assessment of the recent incidence trends of ESCC showed a generally decreasing incidence in men during the last decade, although it is still high in some populations, including Japan (three regions), France (Calvados), and China (Hong Kong). The incidence is generally lower in women 

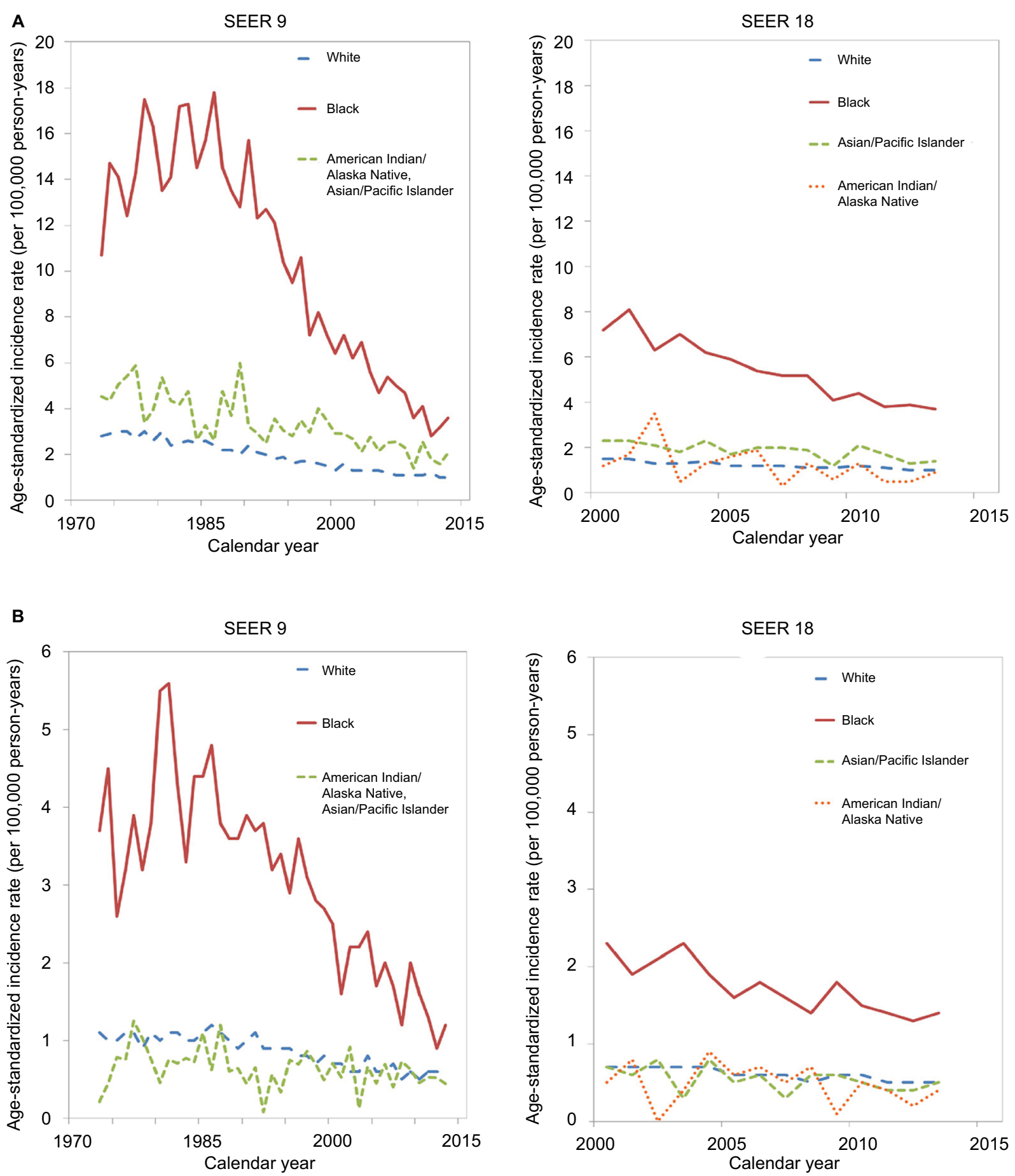

Figure 4 Age-standardized incidence rates of esophageal squamous cell carcinoma in the United States by ethnicity in men (A) and women (B). Abbreviation: SEER, The Surveillance, Epidemiology and End Results.

than in men, but some countries have increased incidence in women - that is, Japan (three regions), the Netherlands, New Zealand, Norway, and Switzerland. The incidence has decreased more rapidly in blacks than in other ethnicities in the United States.

A decreasing incidence of ESCC globally in men has been reported previously, ${ }^{6,11-19}$ and the present study indicated a continuous decrease during recent years. A study using incidence data from 12 countries in 1988-2007 predicted a continuing decrease in the incidence of ESCC in men worldwide, except in Japan, and increasing trends in women in Japan, the Netherlands, Slovakia, and Spain. ${ }^{20}$ That prediction is supported by the updated results of the present study. Increased incidence trends in men have been reported in 
England, the Netherlands, Scotland, and the Nordic countries during the $1980 \mathrm{~s}-1990 \mathrm{~s} ;{ }^{6,15,16,21}$ however, the present study shows that the incidence decreased after the 2000s in these countries. In women, previous studies have reported stable or slightly increasing incidence rates in France, Italy, Norway, Slovenia, and Switzerland before the 2000s, ${ }^{6,11,12,16,19}$ and these trends continued in 2005-2015 in the present study. A slightly increasing incidence has been reported in Swedish and Scottish women in 1980-1997; ${ }^{15}$ however, after this period, the incidence has continued to decrease.

The increasing incidence of ESCC in women in some countries deserves attention. Increased use of endoscopy and improved registration systems might have resulted in an artificially increased incidence due to earlier tumor detection, but it is unlikely that these factors differ between the sexes. Tumor misclassification should be limited and misclassification of ESCC with adenocarcinoma should be uncommon; the proportion of esophageal tumors with unspecified histology was $<20 \%$ in almost all registries. Calendar-period effects were found in women in Norway, whereas birth-cohort effects were found in women in Japan, the Netherlands, and Switzerland and could have contributed to the increase. The age-period-cohort analysis indicated that the increasing incidence in women from Japan and Norway could continue during the coming decades, whereas the incidence in Dutch and Swiss women could decline. Additionally, changes in the prevalence of risk factor exposure may influence the increasing incidence rates in women in some countries. An increased prevalence of smoking has been reported in Swiss women (from $20.6 \%$ in 1980 to $26.1 \%$ in 1998), which could explain the increasing incidence until 2012, but this trend might change due to the sharp drop in tobacco smoking after $1998 .{ }^{22}$ Dutch women have had a slight increase in smoking prevalence (from $23.4 \%$ to $25.9 \%$ in $1980-1990$ ), and a moderate decrease after 1990, which corresponds to the increasing incidence of ESCC reported in the present study and a predicted future decreasing trend. ${ }^{22}$ However, the increased incidence in Japanese women does not correspond with the stable prevalence of tobacco smoking (11.0-12.0\% in 1980-2005). ${ }^{22}$ On the other hand, the prevalence of alcohol consumption among Japanese women increased from $6.3 \%$ to $9.4 \%$ in $1989-1998,{ }^{23}$ which could contribute to the increase, particularly because the use of spirits, which is a stronger risk factor for ESCC than other alcoholic beverages, composed almost half of the total alcohol consumption in Japan. ${ }^{24}$ In Norwegian women, the tobacco smoking prevalence was stable at $27.0 \%$ in $1980-1991$ and decreased to $15.9 \%$ in $2010,{ }^{22}$ and the alcohol consumption has remained stable, ${ }^{25}$ indicating a role for other factors in explaining the increasing incidence of ESCC.

The generally decreasing incidence trends of ESCC in men from around the 1990s onwards could be explained by the globally declining smoking prevalence in men since 1980. ${ }^{22,26}$ Additionally, the trends in alcohol consumption have been decreasing or stable from 1980s onwards. ${ }^{27,28}$ The increasing incidence of ESCC in Japan over time before 2005 is in contrast to the decreasing smoking prevalence, ${ }^{22,23}$ but can be explained by the increasing prevalence of alcohol consumption. ${ }^{28}$

The higher incidence of ESCC in black men than in other ethnicities in the United States could be explained by the higher smoking prevalence compared with other ethnicities. ${ }^{29}$ The decreasing incidence in all ethnicities assessed is in accordance with the declining smoking prevalence in the United States. ${ }^{22}$ However, in black women, the smoking prevalence is similar to that of white women and the alcohol consumption is lower. ${ }^{30}$ The distinct incidence time trends among women of different ethnic groups might be explained by other factors (eg, diet). ${ }^{31,32}$

To the best of our knowledge, this is the most comprehensive and updated study examining the global incidence trends of ESCC. Strengths include the direct data collection from cancer registries of high quality and completeness. ${ }^{7}$ Moreover, the age-period-cohort analysis enabled assessment of calendar-period-specific and birth-cohort-specific effects. The lack of nationwide registries in some included countries is among the limitations of this study. Therefore, merging of data from regional registries within the same country was applied. The fact that the registries covered entire countries or large regions meant that we could not separate rural and urban areas. Another limitation was that data on histological tumor type was not accessible from China, except for Hong Kong. The lack of individual data from cancer registries on risk factors (eg, regarding tobacco smoking and alcohol consumption) prohibited direct analyses of potential reasons for the observed change in incidence trends of ESCC, which however were indirectly analyzed and indicated by the ageperiod-cohort model in the study.

Monitoring the incidence trends of ESCC is of importance for future research and may have public health implications. Tobacco control activities have contributed to the decreasing incidence trends of ESCC in several countries (eg, in Hong Kong, the United States, and several European countries). ${ }^{4,14,33}$ However, more efforts toward alcohol control are proposed, not least in Eastern countries, including Japan. ${ }^{28}$ Despite the decreasing incidence of ESCC in most countries, the inci- 
dence remains high in many populations, and the increasing incidence in women in some countries is worrisome. ${ }^{3}$

\section{Conclusion}

The global incidence of ESCC is decreasing in men, but increasing in women in Japan (three regions), the Netherlands, New Zealand, Norway, and Switzerland. An emphasis on continuous monitoring of the changing epidemiology of ESCC and prioritization of primary prevention of risk factors, including tobacco and alcohol control, is recommended in several populations, not least in women.

\section{Acknowledgments}

This work was supported by the Swedish Research Council (521-2014-2536) and the Swedish Cancer Society (CAN 2015/460). The study sponsors had no role in the study design; collection, analysis, and interpretation of data; the writing of the report; or the decision to submit the manuscript for publication. All of the authors appreciate the assistance in data retrieval from the following persons or registries (presented in alphabetical order):

Dr. Amani Elbasmi (Kuwait Cancer Registry); Mr. Andrew Deas (Scottish Cancer Registry); Ms. Anita Feller (National Institute for Cancer Epidemiology and Registration, Switzerland); Mr. Brian Stokes (Tasmanian Cancer Registry (Australia); Mr. Chris Lewis (New Zealand Cancer Registry); Cancer Institute New South Wales (Australia); Mr. Edrun Andrea Schnell (Cancer Registry of Norway); Ms. Elizabeth Chalker and Ms. Leah Newman (Australian Capital Territory Cancer Registry, Australia); Finnish Cancer Registry; Prof. Imjai Chitapanarux (Chiang Mai Cancer Registry, Thailand); Dr. Jaume Galceran (Tarragona Cancer Registry, Spain); Ms. Jennifer Lai (Public Health England, United Kingdom); Mr. J. Ramón Quirós (Asturias Cancer Registry, Spain); Dr. Katina D’Onise (South Australian Cancer Registry, Australia); Dr. Kotaro Ozasa (Tumor and Tissue Registry Office Hiroshima, Japan); Prof. Laufey Tryggvadottir (Icelandic Cancer Registry, Iceland); Dr. Manuel Zorzi (Veneto Tumor Registry, Italy); Dr. María José Sánchez Pérez (Granada Cancer Registry, Spain); Dr. Mario Šekerija (Croatian National Cancer Registry); Public Health Wales, United Kingdom; Dr. Roger K.C. Ngan (Hong Kong Cancer Registry, China); Mr. Sander Hogewoning (Netherlands Cancer Registry); Dr. Sandra Deady (National Cancer Registry, Ireland); Dr. Seiki Kanemura (Miyagi Prefectural Cancer Registry, Japan); Surveillance, Epidemiology, and End Results Program, United States; Swedish Cancer Registry; Dr. Timothy Threlfall (Western Australian Cancer Registry,
Australia); Dr. Véronique Bouvier (Registre des Tumeurs Digestives du Calvados, France); Prof. Vesna Zadnik (Cancer Registry of Republic of Slovenia); and Dr. Yuko Akazawa (Nagasaki Prefectural Cancer Registry, Japan).

The study has used data from the Cancer Registry of Norway. The interpretation and reporting of these data are the sole responsibility of the authors, and no endorsement by the Cancer Registry of Norway is intended nor should be inferred.

\section{Disclosure}

All authors report no conflicts of interest in this work.

\section{References}

1. Global Burden of Disease Cancer Collaboration, Fitzmaurice C, Dicker D, Pain A, et al. The Global Burden of Cancer 2013. JAMA Oncol. 2015;1(4):505-527.

2. Arnold M, Soerjomataram I, Ferlay J, Forman D. Global incidence of oesophageal cancer by histological subtype in 2012. Gut. 2015;64(3):381-387.

3. Lagergren J, Smyth E, Cunningham D, Lagergren P. Oesophageal cancer. Lancet 2017; 390(10110):2383-2396

4. Xie SH, Lagergren J. Time trends in the incidence of oesophageal cancer in Asia: variations across populations and histological types. Cancer Epidemiol. 2016;44:71-76.

5. Thrift AP, Whiteman DC. The incidence of esophageal adenocarcinoma continues to rise: analysis of period and birth cohort effects on recent trends. Ann Oncol. 2012;23(12):3155-3162.

6. Castro C, Bosetti C, Malvezzi M, et al. Patterns and trends in esophageal cancer mortality and incidence in Europe (1980-2011) and predictions to 2015. Ann Oncol. 2014;25(1):283-290.

7. WHO. Cancer Incidence in Five Continents Volumes I to X, Indices of Data Quality. 2017. Available from: http://ci5.iarc.fr/CI5I-X/Pages/ Quality_sel.aspx. Accessed July 7, 2017.

8. SEER*Stat Database: Incidence - SEER 9 Regs Research Data, Nov 2015 Sub (1973-2013) 2016. Available from: https://seer.cancer.gov/ data-software/documentation/seerstat/nov2015/. Accessed May 28, 2018.

9. SEER*Stat Database: Incidence - SEER 18 Regs Research Data + Hurricane Katrina Impacted Louisiana Cases, Nov 2015 Sub (2000-2013). 2016. Available from: https://seer.cancer.gov/data-software/documentation/seerstat/nov2015/. Accessed May 28, 2018.

10. Rosenberg PS, Check DP, Anderson WF. A web tool for age-periodcohort analysis of cancer incidence and mortality rates. Cancer Epidemiol Biomarkers Prev. 2014;23(11):2296-2302.

11. Desoubeaux N, Le Prieur A, Launoy G, et al. Recent time trends in cancer of the oesophagus and gastric cardia in the region of Calvados in France, 1978-1995: a population based study. Eur J Cancer Prev. 1999;8(6): 479-486.

12. Launoy G, Faivre J, Pienkowski P, Milan C, Gignoux M, Pottier D. Changing pattern of oesophageal cancer incidence in France. Int $J$ Epidemiol. 1994;23(2):246-251.

13. Yee YK, Cheung TK, Chan AO, Yuen MF, Wong BC. Decreasing trend of esophageal adenocarcinoma in Hong Kong. Cancer Epidemiol Biomarkers Prev. 2007;16(12):2637-2640.

14. Giri S, Pathak R, Aryal MR, Karmacharya P, Bhatt VR, Martin MG. Incidence trend of esophageal squamous cell carcinoma: an analysis of Surveillance Epidemiology, and End Results (SEER) database. Cancer Causes Control. 2015;26(1):159-161.

15. Bosetti C, Levi F, Ferlay J, et al. Trends in oesophageal cancer incidence and mortality in Europe. Int J Cancer. 2008;122(5):1118-1129. 
16. Vizcaino AP, Moreno V, Lambert R, Parkin DM. Time trends incidence of both major histologic types of esophageal carcinomas in selected countries, 1973-1995. Int J Cancer. 2002;99(6):860-868.

17. Feller A, Fehr M, Bordoni A, et al. Trends in incidence of oesophageal and gastric cancer according to morphology and anatomical location, in Switzerland 1982-2011. Swiss Med Wkly. 2015;145:w14245.

18. Xie SH, Mattsson F, Lagergren J. Incidence trends in oesophageal cancer by histological type: an updated analysis in Sweden. Cancer Epidemiol. 2017;47:114-117.

19. Hansen S, Wiig JN, Giercksky KE, Tretli S. Esophageal and gastric carcinoma in Norway 1958-1992: incidence time trend variability according to morphological subtypes and organ subsites. Int J Cancer. 1997;71(3):340-344.

20. Arnold M, Laversanne M, Brown LM, Devesa SS, Bray F. Predicting the future burden of esophageal cancer by histological subtype: International Trends in Incidence up to 2030. Am J Gastroenterol. 2017;112(8):1247-1255.

21. Steevens J, Botterweck AA, Dirx MJ, van den Brandt PA, Schouten LJ. Trends in incidence of oesophageal and stomach cancer subtypes in Europe. Eur J Gastroenterol Hepatol. 2010;22(6):669-678.

22. Tobacco Visualization. Seattle, WA: IHME, University of Washington; 2017. Available from: https://vizhub.healthdata.org/tobacco/. Accessed July 7, 2017

23. Cancer Statistics in Japan-2016:Trends in Consumption of Tobacco, Alcohol and Food. 2016. Available from: http://ganjoho.jp/en/professional/statistics/brochure/2016_en.html. Accessed July 7, 2017.

24. Oze I, Matsuo K, Wakai K, et al; Research Group for the Development and Evaluation of Cancer Prevention Strategies in Japan. Alcohol drinking and esophageal cancer risk: an evaluation based on a systematic review of epidemiologic evidence among the Japanese population. Jpn J Clin Oncol. 2011;41(5):677-692.
25. WHO. Global Health Observatory (GHO) data: Global status report on alcohol and health 2014. Norway. Available from: http://www.who.int/ substance_abuse/publications/global_alcohol_report/profiles/nor.pdf. Accessed July 7, 2017.

26. Enzinger PC, Mayer RJ. Esophageal cancer. $N$ Engl J Med. 2003; 349(23):2241-2252.

27. La Vecchia C, Bosetti C, Bertuccio P, Castro C, Pelucchi C, Negri E. Trends in alcohol consumption in Europe and their impact on major alcohol-related cancers. Eur J Cancer Prev. 2014;23(4):319-322.

28. WHO. Global Health Observatory data repository: recorded alcohol per capita consumption, 1980-1999 by country. 2017. Available from: http:// apps.who.int/gho/data/node.main.A1024?lang=en\&showonly=GISAH. Accessed July 7, 2017.

29. Trinidad DR, Pérez-Stable EJ, White MM, Emery SL, Messer K. A nationwide analysis of US racial/ethnic disparities in smoking behaviors, smoking cessation, and cessation-related factors. Am J Public Health. 2011;101(4):699-706.

30. Jamal A, Homa DM, O'Connor E, et al. Current cigarette smoking among adults - United States, 2005-2014. MMWR Morb Mortal Wkly Rep. 2015;64(44):1233-1240.

31. Qu X, Ben Q, Jiang Y. Consumption of red and processed meat and risk for esophageal squamous cell carcinoma based on a meta-analysis. Ann Epidemiol. 2013;23(12):762 -770 e761.

32. Xie SH, Rabbani S, Petrick JL, Cook MB, Lagergren J. Racial and ethnic disparities in the incidence of esophageal cancer in the United States, 1992-2013. Am J Epidemiol. 2017;186(12):1341-1351.

33. Levy DT, Huang AT, Currie LM, Clancy L. The benefits from complying with the framework convention on tobacco control: a SimSmoke analysis of 15 European nations. Health Policy Plan. 2014;29(8): 1031-1042.
Clinical Epidemiology

\section{Publish your work in this journal}

Clinical Epidemiology is an international, peer-reviewed, open access, online journal focusing on disease and drug epidemiology, identification of risk factors and screening procedures to develop optimal preventative initiatives and programs. Specific topics include: diagnosis, prognosis, treatment, screening, prevention, risk factor modification,

Submit your manuscript here: https://www.dovepress.com/clinical-epidemiology-journa

\section{Dovepress}

systematic reviews, risk and safety of medical interventions, epidemiology and biostatistical methods, and evaluation of guidelines, translational medicine, health policies and economic evaluations. The manuscript management system is completely online and includes a very quick and fair peer-review system, which is all easy to use. 